\title{
What Does Productivity Really Mean? Towards an Integrative Paradigm in the Search for Biodiversity-Productivity Relationships
}

\author{
Liangjun $\mathrm{HU}^{1}$, Qinfeng $\mathrm{GUO}^{2}$ \\ ${ }^{1}$ Northeast Normal University, MOE Key Laboratory for Vegetation Ecology Science, 5268 Renmin \\ Street, Life Science Building, Changchun, Jilin 130021, China; hulj068@gmail.com \\ ${ }^{2}$ USDA FS, Eastern Forest Environmental Threat Assessment Center, 200 WT Weaver Blvd., Asheville, NC 28804, U.S.A.
}

\begin{abstract}
How species diversity relates to productivity remains a major debate. To date, however, the underlying mechanisms that regulate the ecological processes involved are still poorly understood. Three major issues persist in early efforts at resolution. First, in the context that productivity drives species diversity, how the pathways operate is poorly-explained. Second, productivity per se varies with community or ecosystem maturity. If diversity indeed drives productivity, the criterion of choosing appropriate measures for productivity is not available. Third, spatial scaling suggests that sampling based on small-plots may not be suitable for formulating species richness-productivity relationships (SRPRs). Thus, the long-standing assumption simply linking diversity with productivity and pursuing a generalizing pattern may not be robust. We argue that productivity, though defined as 'the rate of biomass production', has been measured in two ways-environmental surrogates and biomass production-leading to misinterpretations and difficulty in the pursuit of generalizable SRPRs. To tackle these issues, we developed an integrative theoretical paradigm encompassing richer biological and physical contexts and clearly reconciling the major processes of the systems, using proper productivity measures and sampling units. We conclude that loose interpretation and confounding measures of productivity may be the real root of current SRPR inconsistencies and debate.
\end{abstract}

Keywords: biodiversity-ecosystem functioning, pathway, plant-plant interaction, sampling effect, scale, species richness

\section{Introduction}

The plant species richness-productivity relationship (SRPR), also known as the diversity-productivity relationship (DPR) or more widely the biodiversity-productivity relationship (BPR), is a central notion of the long-standing biodiversity-ecosystem functioning tenets that fascinate many leading ecologists. Related research includes theoretical models, empirical diversity-manipulation experiments or nature-based observations, or in combination (Cardinale et al., 2009; Gillman and Wright, 2006; Gross and Cardinale, 2007; Hooper et al., 2005; Mittelbach and Scheiner, 2003; Mittelbach et al., 2001; Tilman, 1999; Waide, 1999; Whittaker and Heegaard, 2003; Whittaker, 2010). However, obtained results have been contentious (reviewed by: Hooper et al., 2005; Mittelbach et al., 2001).

First, whether plant community diversity depends on productivity, or productivity depends on diversity, or both simultaneously affect each other (Cardinale et al., 2006; Tilman, 1999; Tilman et al., 1996) is still a major debate. It is clear that both variables are simultaneously affected by physical factors, component species and their interactions, and even history (Fridley, 2001; Fukami and Morin, 2003; Gross and Cardinale, 2007). Additionally, many underlying mechanisms that regulate ecosystem components have not been identified or well understood. For example, it is commonly asserted that productivity drives species diversity, yet the underlying driving pathways are still underexplained. Second, previous efforts seeking direct causal links between productivity and species diversity and to identify generalizing patterns are often based on a simple reasoning paradigm with paradoxes and dilemmas (Jiang $e t$ al., 2009; Tilman, 1999). Positive, negative, hump-shaped or unimodal, U-shaped, and not-significant or no single, generalizable relationships have all been reported (Cardinale et al., 2000; Gillman and Wright, 2006; Mittelbach et al., 2001); the positive relationship has been regarded as a main form in manipulated communities, whereas the unimodal or negative relationships are frequently found in natural communities (Jiang et al., 2009; Rajaniemi, 2003).

Past explanations for the inconsistencies and underlying mechanisms behind the SRPRs have included: (1) spatio-temporal scales, such as plot size (Oksanen, 1996), sampling area and timing (Hooper et al., 2005; MacArthur and Wilson, 1967; Moore and Keddy, 1989; Scheiner and Jones, 2002; Whittaker and Heegaard, 2003); (2) sampling or selection probability effect of productive species, plant size, or other 'hidden treatments' (Aarssen, 1997; Fridley, 2001; Huston, 1997; Oksanen, 1996; Wardle, 1999); (3) spatial heterogeneity and disturbance (Car- 
dinale et al., 2000; Grime, 1973; Grubb, 1977; Maranon and Garcia, 1997; Pianka, 1966); (4) life history or successional stage or assembly maturity (Fischer, 1960; Fukami and Morin, 2003; Guo, 2005; Partel et al., 2007; Thompson et al., 2005; Zobel and Partel, 2008); (5) species pool (Hillebrand and Blenckner, 2002; Safford, 2001; Taylor et al., 1990; Weiher, 1999; Weiher and Howe, 2003); and (6) dispersal limitation (Zobel and Partel, 2008), etc. Meanwhile, many variables such as soil resource / fertility (Baer et al., 2003; Fridley, 2002), precipitation (Kay et al., 1997; Rey-Banayas and Scheiner, 2002; Whittaker and Heegaard, 2003), actual evapotranspiration (AET; Rosenzweig, 1995), potential evapotranspiration (PET; Hawkins et al., 2003), biomass production (Gillman and Wright, 2006) and energy (Hutchinson, 1959; Wright, 1983) have been used as surrogates of productivity. However, so far, no substantial consensus has been reached.

Using a 'standardized' field-scale plot sampling across the globe, Adler $e$ al. (2011) recently claim that productivity is a poor predictor for species richness, with no exceptions within sites, within regions, or across the globe. They suggest that investigations should focus on the complex and multivariate processes that regulate both productivity and richness. However, after collectively reading over 500 published articles centred on this subject and only based on a terminological examination of productivity in the DPR assumption, we are doubtful whether the scientific community has asked the right questions and used appropriate methodology. For example, does habitat productivity actually drive diversity, and how? If diversity indeed drives productivity, how do we choose the time during a year and successional stage to harvest the biomass that measures productivity? What are the primary drivers for both diversity and productivity? Have we rigorously defined proper measures for productivity? Thus, in particular we suspect that there are no robust grounds for the long-standing DPR assumption that attempts to relate biodiversity directly to productivity and to search for generalizing patterns (e.g., Tilman, 1999), because it may be missing certain fundamental elements.

Here, in contrast to previous claims, we carefully reexamine the terminology and measures of productivity. We argue that the real root leading to current SRPR controversies may simply rest in the misinterpretation, inappropriate use of variable surrogates, and even an inherent complexity in the definition of productivity per se. These problems are also probably due to a flawed or unjustifiable theoretical paradigm. Therefore, the objective of this analysis is to generate an integrative paradigm that can direct future SRPR formulations. It may also help elucidate the root mechanisms underlying current SRPR debates and, eventually, draw more persuasive SRPRs (e.g., explain whether there is a generalized pattern and if the original DPR assumption is robust).

\section{What does productivity really mean?}

Productivity was originally defined as the rates of biomass production within an ecological assemblage (Fridley, 2001). However, the evidently casual use, misuse, and even abuse, of the term productivity have all been seen in determination of SRPR.

To date, there have been two major schools for using and interpreting the concept productivity. One follows the original definition of biomass production. However, this obviously produces a paradox, i.e., if productivity drives biodiversity, what are the driving pathways that link biomass production and diversity in the system? Additionally, can living biomass alone operate as an environmental context that drives species diversity or other variables? In this regard, the answer would be negative. The only biomass production that can be a direct driving resource will reside in the litter, which can in fact be included as a fertility input (Wardle et al., 1997). Taking the view that productivity drives richness, productivity may have been mistakenly viewed as a dominant driver of richness, which has confounded the role of productivity and the real driver behind it. Thus, the widely used annually harvested biomass-based productivity in formulating SRPRs (e.g., Bai $e t$ al., 2007; Chase and Leibold, 2002; Guo and Berry , 1998) may need to be re-considered. On the other hand, if species richness indeed drives productivity, choosing the right time during the growing season and successional stage in which to measure productivity is another challenge (Guo, 2005; Thompson et al., 2005). Therefore, this inherent complexity in the definition of productivity may raise a need to build a criterion for selecting a proper productivity measure.

The other school interprets productivity using resource supply or environmental surrogates (see reviews and metaanalyses by Gillman and Wright, 2006; Mittelbach et al., 2001; Whittaker, 2010). This raises other questions, i.e., do resource supply and biomass production both play the same role, and can productivity be simply replaced by those surrogates? Since resource supply often operates as a driving force in a system, whereas biomass production is usually the resulting product, the answer may be linked to an 'indirect' effect. It is highly probable that these surrogates can impact the performance of SRPRs. However, there has rarely been any rigorous and clear terminological examination of the definition of productivity. Although caution on the use of biomass as a surrogate for productivity has been expressed (Gillman and Wright, 2006; Grace, 1999), little has been done to assess the likely consequences of using these diverse 'productivity' measures on SRPRs. Researchers often use a biomass-based productivity measure, owing to its easy measurability, e.g., above-ground net primary production (ANPP; in some cases, maximized ANPP during the year) (Gillman and Wright, 2006) or other 
38

environmental measures (e.g., resource supply) based on their requirements. In particular, higher resource availability usually means higher productivity (e.g., the latitudinal gradient of productivity). Therefore, resource supply or environmental context and biomass-based productivity have been confounded with rare exceptions (Cardinale et al., 2009; Gross and Cardinale, 2007). This ill-defined use of productivity measures or surrogates may alter SRPRs. In effect, biomass only accounts for a small proportion of variation in species richness (Grace, 1999), relative to other surrogates of productivity (Gillman and Wright, 2006).

Apart from the above, the presumed DPR assumption that simply relates biodiversity to productivity may have strengthened the confounding effects. In a highly simplified paradigm, much attention may have been paid to within-system elements (e.g., diversity and productivity only), while other critical constituents are neglected. In this light, the flawed paradigm may have hidden consequences. This may be the real 'devil in the detail' that determines how the debate may be settled.

\section{What productivity measure do we need?}

However, if we are to continue an interest in the better assessment of SRPRs, it is critical to evaluate the two schools of productivity measures.

Firstly, an environmental surrogate such as resource supply indeed works well as representing productivity statistically on some occasions; however, it remains difficult to find a specified and, ideally, exclusive measure to describe the exact resource supply performance that decides the SRPR. This is mainly because the surrogates themselves should reflect the environmental resource availability that a system can provide to the organisms it contains. Other resource measures such as soil fertility, energy, precipitation, do not meet such a criterion. For instance, precipitation plays a critical role in regulating plant growth, particularly in water-limiting areas. Yet, what really takes influences on the plant is not the overall precipitation, but only the available part of it which the plant utilizes.

Secondly, environmental surrogates should reflect the pooled availability of all resource sources. Therefore, a single environmental context measure, usually with a respective definition, may not be appropriate for describing the overall supply availability within a system. In fact, this has proven to be the case in field experiments which show that nitrogen addition can cause species and/or biomass loss (Crawley et al., 2005; Gough et al., 2000; Suding et al., 2005). In this respect, the difficulty of distilling an ideal environmental surrogate, or in other words, the use of diverse surrogates of productivity, would lead to skewed or varied SRPRs (Gillman and Wright, 2006).

Thirdly, there is significant variation in biomass production both within a growing season and across successional stages. For example, mature and immature assemblages support different plant traits, biodiversity, and ecosystem functioning (Guo, 2005; Thompson et al., 2005). Given no dramatic environmental fluctuation or disturbance in early succession, both species diversity and biomass production would increase through positive interactions (Callaway, 1995), leading to a positive SRPR. In contrast, in late succession, biomass production remains at a relatively high level and species diversity declines due to competitive exclusion, leading to a negative (Thompson et al., 2005) or other forms (Fridley, 2001; Huston, 1997; Jiang et al., 2009) of SRPR. Since most diversity-manipulated communities are still in early assembly stages (Jiang et al., 2009), a positive SRPR is common.

Since it is difficult to separate the effects of species and environmental context on biomass production during the immature stage, we suggest that the measure should be limited within the mature stage of succession (Thompson et al., 2005). On the other hand, an exact sampling time point during the growth period should also be decided. Since there is asynchrony in biomass production over a year (Hector $e t$ al., 2010), the widely used ANPP measure might be challenged. Here, we suggest an exact measure that takes into account a yearly summed ANPP of all plant species in the mature assemblage.

Fourthly, even using the selected productivity measure, there is still a difficulty in obtaining it in widely used diversity-manipulation experiments, e.g., the BIODEPTH (Hector et al., 2007) and Cedar Creek (Tilman, 1996) experiments. This is because in experiments such as these community maturity is extremely difficult to judge, even after many years of continuing observation, not to mention that Hector et al. (2007) use only three years of observation in defence against critiques made by Thompson et al. (2005). Since any such experiment can be seen as an independent and episodic event during long-term succession, it is therefore unfortunately the case that no one can really know how long a successional stage will last, even in a relatively stable environment. Therefore, the field plotscale experiments, especially those in early succession, are manifestly difficult to extend to vast natural and artificial assemblages, and may thus be inappropriate for drawing SRPRs. Though long-term experimentation (through permanent plots) has been considered as a solution to this problem (Bakker et al., 1996), the space-for-time substitution, based on systematic succession expertise at varied scales, e.g., the climax theory, may be more useful (Pickett, 1989).

\section{Scale justification}

The issues raised above call for a new and integrated paradigm in the search for more convincing SRPRs. Apart from the afore-mentioned selection of a suitable measure for productivity, scaling is another critical factor that is required for consolidation of the theoretical foundation. 
Multi-scaled research efforts have generated inconsistent SRPR patterns, which have also invoked a viewpoint that SRPRs are scale-dependent (Chalcraft et al., 2004; Chase and Leibold, 2002; Gillman and Wright, 2006). However, underlying mechanisms that explain whether those inconsistencies are caused by scaling factors or by other factors, e.g., the sampling effect, are not yet clear. Here, unlike many other related issues, we argue that a fundamental question must first be asked: what scales would be proper or acceptable for drawing SRPRs? Can we draw SRPRs directly based on field plot sampling that pertains to spatial ecology (Loreau et al., 2003)? Or similarly, can we work at a random scale or at spatially multiple scales? This can in fact be answered well by the research of Oksanen (1996), Aarssen (1997), Wardle (1999) and Fridley (2001), if correctly interpreted and extended.

Oksanen (1996) stressed the effects of small quadratplot size and plant size within the plot when interpreting an acquired unimodal pattern (Maranon and Garcia, 1997). This effect is also called the sampling effect caused by productive species (Aarssen, 1997; Wardle, 1999). In Oksanen (1996), two basic components, small quadratplot and diversified plant size, are required to be available at the same time in order for sampling effect to occur. However, sampling effect would be inevitable, so long as we use small field sampling plots, because plot size is always limited and spatial heterogeneity is ubiquitous, leading to 'hidden treatments' (Huston, 1997). In this respect, the sampling effect should not be viewed as a diversity effect (Naeem, 1999; Tilman et al., 1997; Tilman, 1999), consistent with Wardle (1999).

We thus suggest two methodologies that use ideal 'plots' which would generate no sampling effect in determining a presumed generalizable SRPR. One is the broader scale across-ecosystem method, seeking relationships between large-scale beta or gamma diversity and macroscopic productivity over large areas, e.g., across the globe. Here, the 'plot' unit would be an individual ecosystem. In contrast, the other methodology is based on microcosm experiments (Cadotte, 2006; Fox and McGrady-Steed, 2002; Jiang and Patel, 2008). Interestingly, this has been supported by major evidence from previous large scale SRPR studies and microcosm experiments. For instance, meta-analyses by Mittelbach et al. (2001), Mittelbach and Scheiner (2003) and Gillman and Wright (2006) all indicate that SRPRs have an evident converging trend towards fewer patterns (positive and unimodal) or to a positive pattern when spatial scales change from landscape to local, regional, continental and up to global scales. Particularly, this convergence is enhanced when scale changes at the larger limits, e.g., from the continental to global scale, becoming more pronounced when biomass-species richness studies are excluded (Gillman and Wright, 2006). However, differently from the common interpretations of SRPRs being scale-dependent (Chalcraft et al., 2004; Gillman and Wright, 2006), we argue that SRPRs may not be linked to scale-dependency, but instead should be built on enclosed-system-based 'plots'. In other words, SRPRs cannot be addressed at randomly selected spatio-temporal scales.

In Adler et al. (2011), the sampling procedure has been standardized; however, it still pertains to the field scale plot-based sampling method, which, as mentioned before, cannot eliminate sampling effects. Also, the 'standardized' sampling within sites, within regions, and across the globe (with only 48 plant communities sampled) used in the study only considers alpha diversity, not beta diversity. Therefore, although regional and global scales are referred to and no single and generalizable SRPR is found, the across-scale SRPRs still need to be re-examined. Moreover, using an unjustified productivity measure may have generated substantial 'noise' in the obtained SRPRs. Testing whether productivity is a good predictor of richness cannot rely solely on "standardized" sampling, as the terminological issue still persists.

\section{An integrative research paradigm}

To test the robustness of DPR assumptions linked to SRPRs, we need a new integrative paradigm with the following highlights.

(1) SRPRs should be fully addressed in a richer context with both elementary ecosystem components and clearly formulated linkages amongst them. At least four components, i.e., environmental context (e.g., resource supply), organism traits, biodiversity, and biomass production, and three mechanistic pathways, i.e., resource use, species interaction and litter decomposition, should be included (Baer et al., 2003; Cardinale et al., 2000; Cardinale et al., 2009; Fridley, 2001; Gross and Cardinale, 2007).

(2) Because of the complexity inherent in the definition, productivity should be re-examined using a rigorously defined measure.

(3) An across-ecosystem examination of the relationships between beta diversity and broad scale biomass productivity over large areas, and the microcosm experimentation, should be used.

Environmental context, such as resource supply, has in fact long been found to be a major driver regulating both species diversity and biomass production (Baer et al., 2003; Cardinale et al., 2000; Fridley, 2002). For instance, Dovciak and Halpern (2010) state that, in natural communities, temporary increases in resource availability caused by climatic fluctuation (Frank and McNaughton, 1991; Tilman, 1996) or disturbance (Halpern, 1989; Schoennagel et al., 2005) can lead to the establishment of colonizing species, rather than to simple repartitioning of resources among resident species (Belote et al., 2008; Davis et al., 2000; Dovciak et al., 2005). While diversity effects, typically interactive mechanisms such as competitive exclusion and facilitation (Cardinale et al., 2006, 2009; Hector and Schmid, 1999; Naeem et al., 1994; Schwartz et al., 2000; 
40

Srivastava and Vellend, 2005; Tilman et al., 1997), it may only be secondary in regulating productivity relative to environmental context (Ives and Carpenter, 2007; McCann, 2000). Recently, the multivariate productivity-diversity hypothesis (MPD) has been proposed to reconcile the two contrasting perspectives on whether productivity drives diversity and vice versa (Cardinale et al., 2009; Fridley, 2001; Gross and Cardinale, 2007; Loreau et al., 2001; Schmid, 2002). Referring to it, we develop an integrative paradigm for the future formulation of SRPRs, as follows (Fig. 1).

In contrast to Cardinale et al. (2009) and other multivariate efforts for SRPR formulation, in this new paradigm a measure of productivity has been rigorously defined, justifiable research methods have been examined, and biodiversity and productivity are seen as two of many attributes of organismal assemblages (McCann, 2000). Here, biodiversity encompasses not only species number in the traditional sense, but also many new elements, e.g., abundance, composition, and functional roles (Cadotte, 2011; Petchey and Gaston, 2002), depending on the methodologies.

Additionally, the new paradigm encompasses environmental context as the primary driver of both biodiversity and biomass production through resource use pathways by organisms. Biodiversity, as a secondary driver, can affect biomass production through species interactions (e.g., both inter-specific and intra-specific competition and facilitation). However, biomass cannot directly influence biodiversity, but rather does so indirectly through altering the decomposition of litter and thus the resource supply (Fig. 1). This process may be relatively weak because it depends on decomposition conditions (e.g., microbial activity, soil fertility, soil moisture, temperature). However, the long-term accumulative effects may be more profound.
In addition, even under normal conditions at a singletrophic level, environmental fluctuations and diversified species interactions would complicate the shape of SRPRs. Under more complicated conditions, perturbations would affect both environmental context and assembled organisms, and stocking/predation relationships at multiple trophic levels would also influence organisms, which would reshape the performance of the SRPRs. Thus, the new paradigm strongly implies that there may not after all be a generalizable and persistent SRPR.

\section{Concluding remarks}

To date, much vigour in ecological research may have been devoted in vain to what has been thought to be a 'major debate', which in effect may rather be only a result of the loose definitions and improper measures for productivity, enhanced by a flawed or vague DPR assumption. In fact, to elucidate how the key components within an ecological assemblage link with each other is not a compelling challenge. This situation may be partly caused by our anxiety about ongoing species loss and extinction threat on a global scale, and by the urgency for biodiversity conservation and productivity enhancement, which is in turn linked to food security, carbon sequestration, and thus concerns about global change. However, our arguments regarding SRPRs should be based on the foundation of fact and justified reasoning. A recent trend that emphasizes the role of biodiversity in enhancing the multifunctionality of ecosystems sounds more persuasive and promising (Hector and Bagchi, 2007; Maestre et al., 2012).

We thus draw the following conclusions as:

(1) Productivity has often been misinterpreted in its definition and has been inconsistently measured in draw-

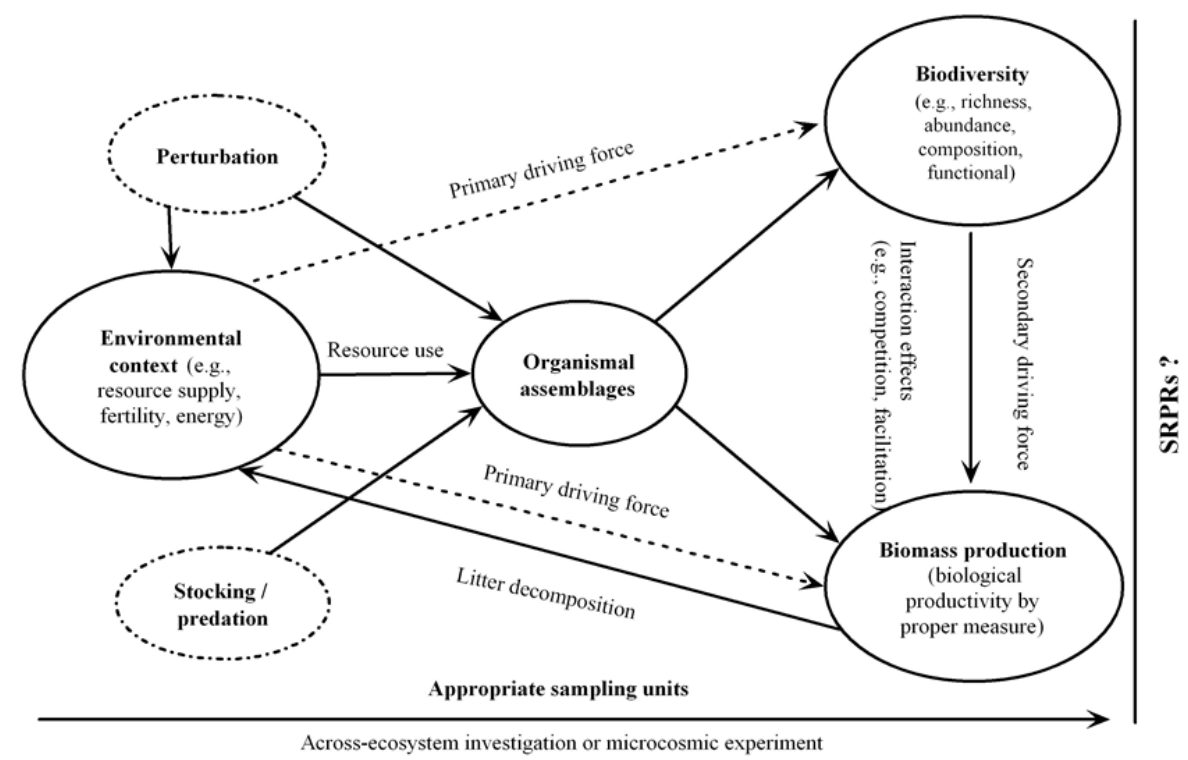

Fig. 1. An integrative single-trophic-level paradigm for SRPR formulations. Major relationships are reconciled among elementary components of ecosystems 
ing SRPRs, which may have contributed much to the ongoing debate. We thus reexamined productivity in order to form a proper measure.

(2) Multi-scaled studies should not suggest scale-dependent explanations; on the contrary, the implication is that the field small-plot may not be appropriate for drawing SRPRs. SRPRs should not be formulated at random scales; instead, only broader scale across-ecosystem investigation and microcosmic experimentation should be used.

(3) SRPRs should be addressed under a new integrative paradigm. In our paradigm, four key components and three mechanistic pathways have been linked with each other and reconciled; environmental context has been viewed as a primary driver of both biodiversity and productivity through resource use pathways, whereas species interactions and litter decomposition become secondary in formulating the SRPRs.

(4) SRPRs change with time, even in the same system, being complicated by the environmental context and species traits/interactions that are affected by disturbances and stocking/predation. To prompt related biodiversityecosystem functioning research, the old-fashioned DPR assumption may need to be revolutionized.

In short, we would like to restate that a major task for ecology is to isolate cause-effect relationships, such as, SRPRs, in ecosystems where related variables, processes, and patterns can be appropriately identified, measured, and characterized. While identifying a common model is useful, it is time for us to admit that there may not be a single or universal SRPR, because of its highly habitat- and timespecific nature. We hope that, with additional efforts on the right track, a new generation of SRPRs can be placed on a solid foundation and soon come of age.

\section{Acknowledgments}

This research is supported by the National Natural Science Foundation of China programme (grant No. 41071189), the Jilin Provincial Personnel Affairs Services programme for Sci-Tech Innovation Activities by Talents with Overseas Study Record, and the Jilin Provincial SciTech Services International Joint Research programme (grant No. 20090713). Thanks are also owed to China Scholarship Council (CSC) for supporting this one-year visiting research project at Purdue University, and to ChiHua Huang for hosting LJH to initiate this research at the USDA-ARS National Soil Erosion Research Laboratory, West Lafayette, Indiana, U.S.A.

\section{References}

Aarssen LW (1997). High productivity in grassland ecosystems: effected by species diversity or productive species? Oikos 80:183-184.

Adler PB, Seabloom EW, Borer ET, Hillebrand H, Hautier Y, Hector A (2011). Productivity is a poor predictor of plant species richness. Science 333:1750-1753.
Baer SG, Blair JM, Collins SL, Knapp AK (2003). Soil resources regulate productivity and diversity in newly established tallgrass prairie. Ecology 84:724-735.

Bai Y, Wu J, Pan Q, Huang J, Wang Q, Li F, Buyantuyev A, Han $X$ (2007). Positive linear relationship between productivity and diversity: evidence from the Eurasian Steppe. J Appl Ecol 44:1023-1034.

Bakker JP, Olff H, Willems JH, Zobel M (1996). Why do we need permanent plots in the study of long-term vegetation dynamics? J Veg Sci 7:147-156.

Belote RT, Jones RH, Hood SM, Wender BW (2008). Diversity-invasibility across an experimental disturbance gradient in Appalachian forests. Ecology 89:183-192.

Cadotte MW (2006). Metacommunity influences on community richness at multiple spatial scales: a microcosm experiment. Ecology 87:1008-1016.

Cadotte MW (2011). The new diversity: management gains through insights into the functional diversity of communities. J Appl Ecol 48:1067-1069.

Callaway RM (1995). Positive interactions among plants. Bot Rev 61:306-349.

Cardinale BJ, Bennett DM, Nelson CE, Gross K (2009). Does productivity drive diversity or vice versa? A test of the multivariate productivity-diversity hypothesis in streams. Ecology 90:1227-1241.

Cardinale BJ, Nelson K, Palmer MA (2000). Linking species diversity to the functioning of ecosystems: on the importance of environmental context. Oikos 91:175-183.

Cardinale BJ, Weis JJ, Forbes AE, Tilmon KJ, Ives AR (2006). Biodiversity as both a cause and consequence of resource availability: a study of reciprocal causality in a predator-prey system. J Anim Ecol 75:497-505.

Chalcraft DR, Williams JW, Smith MD, Willig MR (2004). Scale dependence in the species-richness-productivity relationship: the role of species turnover. Ecology 85:27012708.

Chase JM, Leibold MA (2002). Spatial scale dictates the productivity-biodiversity relationship. Nature 416:427-430.

Crawley MJ, Johnston AE, Silvertown J, Dodd M (2005). Determinants of species richness in the Park Grass Experiment. Am Nat 165:179-192.

Davis MA, Grime JP, Thompson K (2000). Fluctuating resources in plant communities: a general theory of invasibility. J Ecol 88:528-534.

Dovciak M, Frelich LE, Reich PB (2005). Pathways in old-field succession to white pine: seed rain, shade, and climate effects. Ecol Monogr 75:363-378.

Dovciak M, Halpern CB (2010). Positive diversity-stability relationships in forest herb populations during four decades of community assembly. Ecol Lett 13:1300-1309.

Fischer AG (1960). Latitudinal variations in organic diversity. Evolution 14:64-81.

Fox JW, McGrady-Steed J (2002). Stability and complexity in 
42 microcosm communities. J Anim Ecol 71:749-756.

Frank DA, McNaughton SJ (1991). Stability increases with diversity in plant communities: empirical evidence from the 1988 Yellowstone drought. Oikos 62:360-362.

Fridley JD (2001). The influence of species diversity on ecosystem productivity: how, where, and why? Oikos 93:514-526

Fridley JD (2002). Resource availability dominates and alters the relationship between species diversity and ecosystem productivity in experimental plant communities. Oecologia 132:271-277.

Fukami T, Morin PJ (2003). Productivity-biodiversity relationships depend on the history of community assembly. Nature 424:423-426.

Gillman LN, Wright SD (2006). The influence of productivity on the species richness of plants: a critical assessment. Ecology 87:1234-1243.

Gough L, Osenberg CW, Gross KL, Collins SL (2000). Fertilization effects on species density and primary productivity in herbaceous plant communities. Oikos 89:428-439.

Grace JB (1999). The factors controlling species density in herbaceous plant communities: an assessment. Perspect Plant Ecol Evol Syst 2:1-28.

Grime JP (1973). Competitive exclusion in herbaceous vegetation. Nature 242:344-347.

Gross K, Cardinale BJ (2007). Does species richness drive community production or vice versa? Reconciling historical and contemporary paradigms in competitive communities. Am Nat 170:207-220.

Grubb PJ (1977). The maintenance of species richness in plant communities: the importance of the regeneration niche. Biol Rev 52:107-145.

Guo Q (2005). Plant communities: ecosystem maturity and performance. Nature 435:E6.

Guo Q, Berry W (1998). Species richness and biomass: dissection of the hump-shaped relationships. Ecology 79:25552559.

Halpern CB (1989). Early successional patterns of forest species: interactions of life history traits and disturbance. Ecology 70:704-720.

Hawkins BA, Porter EE, Diniz-Filho JAF (2003). Productivity and history as predictors of the latitudinal diversity gradient of terrestrial birds. Ecology 84:1608-1623.

Hector A, Bagchi R (2007). Biodiversity and ecosystem multifunctionality. Nature 448:188-190.

Hector A, Hautier Y, Saner P (2010). General stabilizing effects of plant diversity on grassland productivity through population asynchrony and overyielding. Ecology 91:2213-2220.

Hector A, Joshi J, Scherer-Lorenzen M (2007). Biodiversity and ecosystem functioning: reconciling the results of experimental and observational studies. Funct Ecol 21:998-1002.

Hector A, Schmid B (1999). Plant diversity and productivity experiments in European grasslands. Science 286:1123-1127.
Hillebrand H, Blenckner T (2002). Regional and local impact on species diversity-from pattern to processes. Oecologia 132:479-491.

Hooper DU, Chapin III FS, Ewel JJ (2005). Effects of biodiversity on ecosystem functioning: a consensus of current knowledge. Ecol Monogr 75:3-35.

Huston MA (1997). Hidden treatments in ecological experiments: re-evaluating the ecosystem function of biodiversity. Oecologia 110:449-460.

Hutchinson GE (1959). Homage to Santa Rosalia or why are there so many kinds of animals? Am Nat 93:145-159.

Ives AR, Carpenter SR (2007). Stability and diversity of ecosystems. Science 317:58-62.

Jiang L, Patel SN (2008). Community assembly in the presence of disturbance: a microcosm experiment. Ecology 89:19311940.

Jiang L, Wan S, Li L (2009). Species diversity and productivity: why do results of diversity-manipulation experiments differ from natural patterns? J Ecol 97:603-608.

Kay RF, Madden RH, Van Schaik C, Higdon D (1997). Primate species richness is determined by plant productivity: implications for conservation. PNAS 94:13023-13027.

Loreau M, Mouquet N, Holt RD (2003). Meta-ecosystems: a theoretical framework for a spatial ecosystem ecology. Ecol Lett 6:673-679.

Loreau M, Naeem S, Inchausti P (2001). Biodiversity and ecosystem functioning: current knowledge and future challenges. Science 294:804-808.

MacArthur RH, Wilson EO (1967). The theory of island biogeography. Princeton University Press, Princeton, New Jersey, USA.

Maestre FT, Quero JL, Gotelli NJ (2012). Plant species richness and ecosystem multifunctionality in global drylands. Science 335:214-218.

Maranon T, Garcia LV (1997). The relationship between diversity and productivity in plant communities: facts and artefacts. J Ecol 85:95-96.

McCann KS (2000). The diversity-stability debate. Nature 405:228-233.

Mittelbach GG, Scheiner S (2003). What is the observed relationship between species richness and productivity? Reply Ecology 84:3390-3395.

Mittelbach GG, Steiner CF, Scheiner SM. (2001). What is the observed relationship between species richness and productivity? Ecology 82:2381-2396.

Moore DRJ, Keddy PA (1989). The relationship between species richness and standing crop in wetlands: the importance of scale. Vegetatio 79:99-106.

Naeem S (1999). Biodiversity and ecosystem function: maintaining natural life support processes. Issue Ecol 4:1-12.

Naeem S, Thompson LJ, Lawler SP, Lawton JH, Woodfin RM (1994). Declining biodiversity can alter the performance of 
ecosystems. Nature 368:734-737

Oksanen J (1996). Is the humped relationship between species richness and biomass an artefact due to plot size? J Ecol 84:293-295.

Pärtel M, Laanisto L, Zobel M (2007). Contrasting plant productivity-diversity relationships across latitude: the role of evolutionary history. Ecology 88:1091-1097.

Petchey OL, Gaston KJ (2002). Functional diversity (FD), species richness and community composition. Ecol Lett 5:402411.

Pianka ER (1966). Latitudinal gradients in species diversity: a review of concepts. Am Nat 100:33-46.

Pickett STA (1989). Space-for-time substitution as an alternative to long-term studies, 110-135 p. In: Likens GE (Ed.). Long term studies in Ecology: approaches and alternatives. Springer-Verlag, New York, USA.

Rajaniemi TK (2003). Explaining productivity-diversity relationships in plants. Oikos 101:449-457.

Rey-Banayas JM, Scheiner SM (2002). Plant diversity, biogeography and environment in Iberia: patterns and possible causal factors. J Veg Sci 13:245-258.

Rosenzweig ML (1995). Species diversity in space and time. Cambridge University Press, Cambridge, UK.

Safford HDF, Rejmanek M, Hadac E (2001). Species pools and the "hump-back" model of plant species diversity: an empirical analysis at a relevant spatial scale. Oikos 95:282-290.

Scheiner SM, Jones S (2002). Diversity, productivity and scale in Wisconsin vegetation. Evol Ecol Res 4:1097-1117.

Schmid B (2002). The species richness-productivity controversy. Trend Ecol Evol 17:113-114.

Schoennagel T, Veblen TT, Romme WH, Sibold JS, Cook ER (2005). ENSO and PDO variability affect drought-induced fire occurrence in Rocky Mountain subalpine forests. Ecol Appl 15:2000-2014.

Schwartz M, Brigham C, Hoeksema J, Lyons K, Mills M, Van Mantgem P (2000). Linking biodiversity to ecosystem function: implications for conservation ecology. Oecologia 122:297-305.

Srivastava DS, Vellend M (2005). Biodiversity-ecosystem function research: is it relevant to conservation? Annu Rev Ecol Evol Sys 36:267-294.

Suding KN, Collins SL, Gough L (2005). Functional- and abundance-based mechanisms explain diversity loss due to N fertilization. PNAS 102:4387-4392.
43

Taylor KL, Aarssen LW, Loehle C (1990). On the relationship between $\mathrm{r} / \mathrm{K}$ selection and environmental carrying capacity: a new habitat template for plant life history strategies. Oikos 58:239-250.

Thompson K, Askew AP, Grime JP, Dunnett NP, Willis AJ (2005). Biodiversity, ecosystem function and plant traits in mature and immature plant communities. Funct Ecol 19:355-358.

Tilman D (1999). The ecological consequences of changes in biodiversity: a search for general principles. Ecology 80:1455-1474.

Tilman D, Lehman CL, Thomson KT (1997). Plant diversity and ecosystem productivity: theoretical considerations. PNAS 94:1857-1861.

Tilman D, Wedin D, Knops J (1996). Productivity and sustainability influenced by biodiversity in grassland ecosystems. Nature 379:718-720.

Waide RB, Willig MR, Steiner CF (1999). The relationship between productivity and species richness. Annu Rev Ecol Syst 30:257-300.

Wardle DA (1999). Is "sampling effect" a problem for experiments investigating biodiversity-ecosystem function relationships? Oikos 87:403-407.

Wardle DA, Bonner KI, Nicholson KS (1997). Biodiversity and plant litter: experimental evidence which does not support the view that enhanced species richness improves ecosystem function. Oikos 79:247-258.

Weiher E (1999). The combined effects of scale and productivity on species richness. J Ecol 87:1005-1011.

Weiher E, Howe A (2003). Scale-dependence of environmental effects on species richness in oak savannas. J Veg Sci 14:917920.

Whittaker RJ (2010). Meta-analyses and mega-mistakes: calling time on meta-analysis of the species richness-productivity relationship. Ecology 91:522-2533.

Whittaker RJ, Heegaard E (2003).What is the observed relationship between species richness and productivity? Comment. Ecology 84:384-3390.

Wright DH (1983). Species-energy theory: an extension of species-area theory. Oikos 41:96-506.

Zobel M, Pärtel M (2008).What determines the relationship between plant diversity and habitat productivity? Glob Ecol Biogeogr 17:79-684. 